\title{
Malondialdehyde as a Prognostic Marker in Patients with Ovarian Adenocarcinoma
}

\author{
OANA TRIFANESCU1,2, MARIA IULIANA GRUIA ${ }^{1}$, LAURENTIA GALES ${ }^{1,2}$, RALUCA TRIFANESCU ${ }^{2,3 *}$, ALINA MIHAELA PASCU4*, \\ VLADIMIR POROCH ${ }^{5,6 *}$, SEBASTIAN TOMA ${ }^{4}$, CATALINA POIANA ${ }^{2,3}$, RODICA ANGHEL ${ }^{1,2}$ \\ 1Prof. dr. Alexandru Trestioreanu Institute of Oncology, 252 Fundeni Road, 022328 Bucharest, Romania \\ ${ }^{2}$ Carol Davila University of Medicine and Pharmacy, 8 Eroii Sanitari Str., 050474, Bucharest, Romania \\ ${ }^{3}$ C.I. Parhon National Institute of Endocrinology, 34-36 Aviatorilor Blvd., 011863, Bucharest, Romania \\ ${ }^{4}$ Transilvania University of Brasov, Faculty of Medicine, 29 Eroilor Blvd., 500036, Brasov, Romania \\ ${ }^{5}$ Grigore T. Popa University of Medicine and Pharmacy, Faculty of Medicine, 16 Universitatii Str., 700115, Iasi, Romania \\ ${ }^{6}$ Regional Institute of Oncology, 2-4 G-ral Berthelot Str., 700483, Iasi, Romania
}

\begin{abstract}
Oxidative stress is defined as the imbalance between reactive oxygen species and cellular antioxidative mechanisms. Reactive oxygen species are involved in the development and progression of many cancers and has been showed to activate pro-tumorigenic signalling, increase tumour cell survival, proliferation, invasion and metastasis, DNA damage and genetic instability. These are highly reactive and attack various classes of essentials biomolecules such as proteins, DNA and most important lipids. Malondialdehyde is the best investigated product of lipid peroxidation. The aim of this study was to evaluate the prognostic role of malondialdehyde in patients with ovarian adenocarcinoma and in an experimental model.
\end{abstract}

Keywords: malondialdehyde, lipid peroxidation, reactive oxygen species, ovarian adenocarcinoma

Oxidative stress is defined as a disturbance of the prooxidant versus antioxidant balance in favour of the prooxidant, which leads to a potential tissue damage, or to a molecular damage caused by an attack of the reactive species over the constituents of living organisms [1-3]. Nowadays a new biochemical definition of the oxidative stress emerges as a disruption of the redox signalling and control, and an imbalance between oxidants and antioxidants in favour of the oxidants, leading to changes in the molecular components of the redox system $[1,4]$.

Reactive oxygen species (ROS) are short lives molecules containing unpaired electrons, produced daily in the cells as results of aerobe cellular metabolism and partial reduction of molecular oxygen [5]. They are oxygen containing derivates, highly unstable free radicals like superoxide $\left(\mathrm{O}_{2}{ }^{-}\right)$, hydroxyl $(\mathrm{OH} \bullet)$, peroxyl $\left(\mathrm{RO}_{2} \cdot\right)$ and alkoxyl (RO•), which can be converted into more stable molecules such as hydrogen peroxide $\left(\mathrm{H}_{2} \mathrm{O}_{2}\right.$, and hypochlorous acid ( $\mathrm{HClO})$ [6].

Elevated levels of ROS had been described in many malignancies and are thought to be oncogenic, because it causes damage of the most important constituents of the cell such as DNA, proteins, lipids, and promotes genetic instability and tumorigenesis [7, 8].

ROS act as signalling molecules and promote abnormal tumour growth, invasion and metastasis, resistance to apoptosis and stimulate angiogenesis and adaptation to hypoxia, loss of tumour suppressor gene function, generation of oncogenic mutation and increase glucose metabolism [9].

The most important sources of ROS are increased glucose metabolism (Walburg effect), reduced free radicals scavenging enzymes, increased oncogenic activity, increased secretion of growth factors and cytokines due to increased intracellular oxidant production from the mitochondria, NADPH oxidase (NOX), cyclooxygenase, and xanthine oxidase [6].

ROS are highly reactive and attack various classes of essentials biomolecules such as proteins, DNA and lipids (polyunsaturated fatty acids - PUFAs),

The evaluation of biomarkers of oxidative stress in the patient's serum is difficult and therefore a challenge for the researcher, as mostROS are highly unstable molecules with a half-life of $10^{-6}$ or $10^{-9} \mathrm{~s}$. ROS with a longer life have a half-life of less than one millisecond [10].

Lipid peroxidation is defined as the reaction between ROS and lipids. Malondialdehyde (MDA), 4-hydroxynonenal (HNE), and F2-isoprostane 15(S)-8-isoprostaglandin F2a (15(S)-8-iso-PGF2a) are the best investigated products of lipid peroxidation [11].

MDA or 1,3-propanediol (OHCeCH2eCHO; $\mathrm{C} 3 \mathrm{H} 4 \mathrm{O} 2)$ is a soluble compound at room temperature, with a melting point of $72-74^{\circ} \mathrm{C}$, soluble in water, methanol and ethanol, moderately soluble in methylene chloride and insoluble in diethyl ether [12] .

Numerous studies show that oxidative stress is involved in the pathogenesis of cancer, but its exact role in the occurrence, propagation, metastasis and the acquisition of resistance to chemotherapy in cancer is not fully elucidated.

Epithelial ovarian cancer is the eight cause of cancer in women and the eight cause of cancer death-related worldwide. Ovarian cancer is the second cause of gynaecological cancer-associated death and the third cause of gynaecological cancer, especially because the vast majority of patients present in advanced stages [13, 14].

Patients with ovarian carcinoma have elevated levels of ROS and low levels of antioxidants. The pro-oxidant status is characterized by the increase of pro-oxidant enzymes and the decrease of the antioxidant ones [15].

The aims of this study were to determine the prognostic value of MDA as a marker of lipid peroxidation in patients with ovarian cancer and in tumour cell cultures.

\section{Experimental part}

\section{Materials and methods}

Our prospective study included 40 patients with ovarian cancer treated in Prof. dr. Alexandru Trestioreanu Institute of Oncology, Bucharest between J anuary 2010-December 2017. The inclusion criteria were the following: confirmed serous ovarian carcinoma, stage II-IV according to AJCC, TNM $8^{\text {th }}$ edition and FIGO staging, age more than 18 years, ECOG performance status less than 2, patients who

*email: ralucatrifanescu@yahoo.com; alina.pascu@unitbv.ro; vladimir.poroch@umfiasi.ro 
underwent multimodality treatment consisting in surgery with curative intent and platinum-based chemotherapy (Paclitaxel $175 \mathrm{mg} / \mathrm{m}^{2}$ and Carboplatin AUC 5-6 every 3 weeks). All the patients signed an informed consent approved by the Ethics Committee of the Bucharest Institute of Oncology, in accordance with some published models [16-18].

Blood was collected by venepuncture into vacutainer tubes with or withoutheparin or EDTA and stored at $-20^{\circ} \mathrm{C}$.

To evaluate the lipid peroxidation, MDA was measured before each cycle of chemotherapy. Only patients with 4 determinations were included in the final analysis. MDA was measured using spectrophotometric Carbonneau method. A colored adduct between MDA and thiobarbituric acid (TBA2) was measured at $532 \mathrm{~nm}$ (the peak absorbance of the MDA-TBA2 adduct) - normal values < 0-4 umol / $100 \mathrm{~mL}$ [19].

The database and statistical data analysis were performed using SPSS version 23 for Windows. A descriptive data analysis has been performed and included mean, median, standard deviation, standard error for continuous variables. To compare and assess statistically significant differences between the different categories of variables, the $\chi 2$ test was applied to the dichotomous variables, the Student test for the normal distribution of continuous variables. Survival curves were generated using the Kaplan-Meier method. The various parameters were compared in terms of their influence on survival and interval to disease progression, using the log-rank test univariate analysis. Confidence interval (C.I.) was considered for the quantitative calculation variables of $95 \%$, and the $p$ value considered statistically significant was less than 0.05 .

Receiver Operating Characteristics (ROC) curves were used for evaluating the efficacy of a model and for determining the sensitivity and specificity of the method. The aria under the curve (AUC) closer to 1 predicts a perfect model and the AUC value above 0.6 validates the model in terms of fairness.

\section{Results and discussions}

The mean age at diagnostic of the patients included in our study was $50.5 \pm 7.8$ years, range $42-76$. Stage distribution showed that the majority of the patients presented with locally advanced and metastatic disease (57.5\% of the patients in stage III, $27.5 \%$ in stage IV, and only $5 \%$ in stage II).

Mean value of MDA was $7.94 \pm 3.05 \mu \mathrm{mol} / 100 \mathrm{~mL}$, median $7.42 \mu \mathrm{mol} / 100 \mathrm{~mL}$, range $(2.16-16.83)$.

One can observe a continuous decrease of the MDA mean serum level from the first MDA assay, at the first cycle of chemotherapy $(9.07 \mu \mathrm{mol} / 100 \mathrm{~mL})$ compared to the second determination $(7.78 \mu \mathrm{mol} / 100 \mathrm{~mL}$, not significantly), to the third determination $(7.20 \mu \mathrm{mol} / 100$ $\mathrm{mL}, \mathrm{p}=0.0032)$, and to the fourth one $(7.35 \mu \mathrm{mol} / 100 \mathrm{~mL}$, $p=0.003$ ).

In order to evaluate the prognostic value of MDA in patients with ovarian cancer, progression free survival (PFS) - defined as the time from cancer diagnosis to disease progression or death from any cause - and overall survival (OS) - defined as the time from cancer diagnostic to the date of death due to any cause, or to the date of censoring at the last time the subject was known to be alive in intention-to-treat populations - were calculated. Median follow up was 38 months. In our lot of 40 patients median PFS was 22 months and median OS was 84 months. One- and two-year PFS was $61 \%$, and, respectively, $48 \%$. OS at 24 and 36 months was $92 \%$, and, respectively, $76 \%$ (fig. $1 A$ and $B$ ).

In order to determine the prognostic value of MDA in ovarian cancer patients were divided in 3 groups: patients with MDA less than $8 \mu \mathrm{mol} / 100 \mathrm{~mL}$, between 8-12 $\mu \mathrm{mol} /$ $100 \mathrm{~mL}$, and patients with MDA more than $12 \mu \mathrm{mol} / 100$ $\mathrm{mL}$.

PFS was statistically significant different between the 3 groups: median PFS was 36 months in patients with MDA less than $8 \mu \mathrm{mol} / 100 \mathrm{~mL}$, median PFS was 13 months in patients with MDA between 8-12 $\mu \mathrm{mol} / 100 \mathrm{~mL}$, and median PFS was only 5 months in patients with MDA more than 12 $\mu \mathrm{mol} / 100 \mathrm{~mL}$. The difference was statistically significant between the groups, $p=0.0001$. Increased MDA over 8 $\mu \mathrm{mol} / 100 \mathrm{~mL}$ was associated with an increased risk of PFS (HR $=2.82,95 \%$ C.I. $=2.10-3.80)$.

OS was significantly different between the 3 groups: in the group of patients with MDA less than $8 \mu \mathrm{mol} / 100 \mathrm{~mL}$, median estimated OS was 84 months, in the patients with MDA between 8-12 $\mu \mathrm{mol} / 100 \mathrm{~mL}$, median estimated OS was 55 months, and in the patients with MDA more than $12 \mu \mathrm{mol} / 100 \mathrm{~mL}$, median estimated OS was only 5 months. The difference was statistically significant between the groups, $p=0.002$. Increased MDA over $8 \mu \mathrm{mol} / 100 \mathrm{~mL}$ was associated in COX regression analysis with an increased risk of death $(H R=1.85,95 \%$ C.I. $=1.26-2.73)$ (fig. $2 A$ and $B$ ).

The study also aimed to assess the role of MDA as a prognostic marker. ROC curves were used to estimate the sensibility and specificity of the method. The aria under the curve (AUC) was $0.745, p=0.0001$, with a 95\% C.I. = $0.67-0.81$, demonstrating that serum MDA may be accurately used to estimate the time to progression (PFS). The cut-off value of serum MDA to predict PFS was 5.76

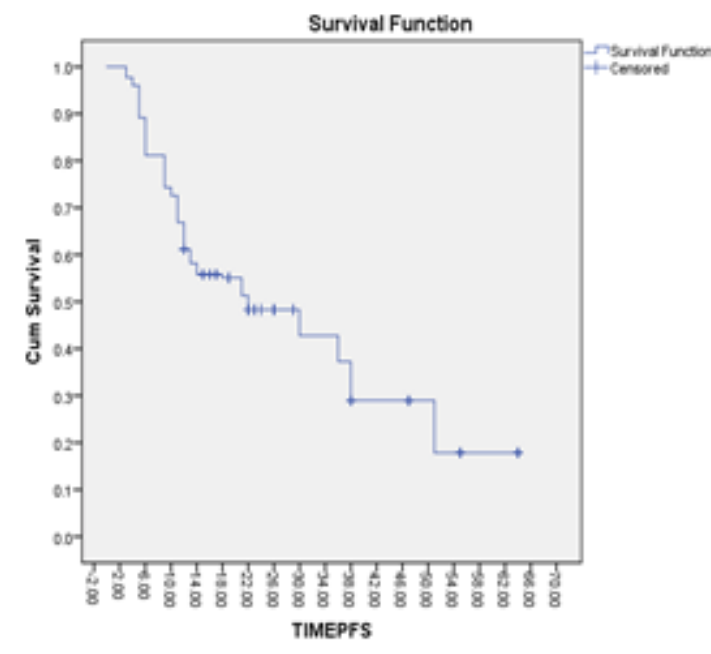

A.

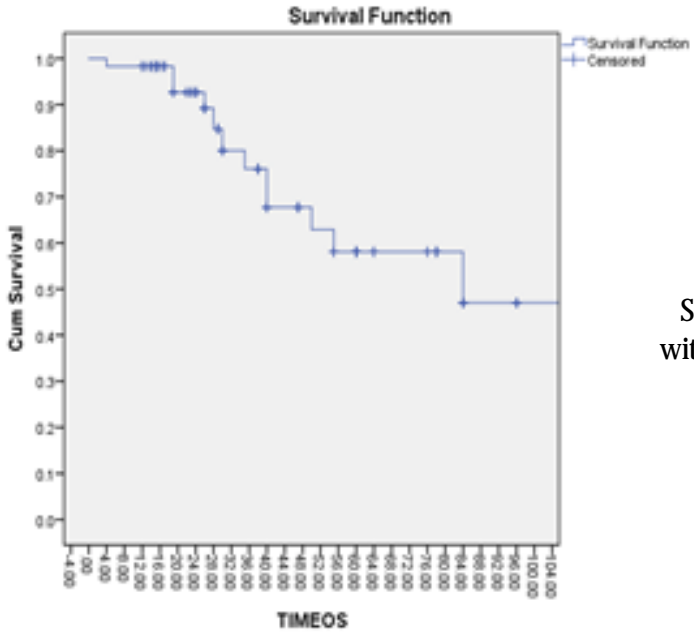

Fig. 1. Progression Free Survival $(A)$ and Overall Survival (B) in the Patients with Ovarian Adenocarcinoma from the Study Group 


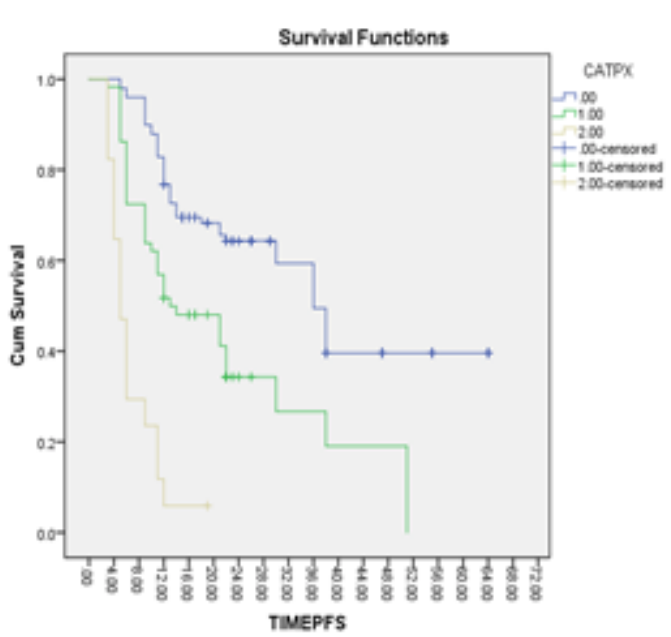

$\mu \mathrm{mol} / 100 \mathrm{~mL}$, with $80 \%$ sensitivity. Regarding overall survival, the AUC was $0.66, p=0.001,95 \%$ C.I. $=0.57$ 0.75 . The cut-off value of serum MDA to predict OS with $80 \%$ sensibility was $6.41 \mu \mathrm{mol} / 100 \mathrm{~mL}$ (fig $3 \mathrm{~A}$ and B).

A study published in 2016 aimed to determine the levels of reactive MDA oxygen species, reactive carbonyl groups (as markers of ROS lesions) and total antioxidants in patients without ovarian carcinoma, with pre-cancerous lesions, and in patients with stage III and IV ovarian carcinoma. The study included 35 patients in whom tissue samples were collected (11 had invasive ovarian adenocarcinoma), MDA and carbonyl groups from frozen tumour tissue were measured by spectrophotometric methods. The study showed that the ROS concentration was $96 \%$ higher in ovarian cancer compared to the control group. There was an exponential increase in MDA values with the transition to malignancy (invasive tumours had a 5 -fold increase in MDA values, ovarian cystadenomas show ed a $50 \%$ increase in ROS production and borderline tumours by $57 \%$ compared to normal tissue). The conclusion of the study was that excess ROS production and increased levels of MDA exceeded the capacity of antioxidant systems and might be a causal factor for the initiation and progression of ovarian carcinoma [20]. These data provided a theoretical basis for the use of ROS as markers for differentiation betw een malignant and benign tumours, as well as the use of antioxidants as a chemoprevention measure.

To counteract the effects of excess activation of ROS and to rebalance the redox balance, the cancer cell changes its homeostasis and oxidative stress appears to be involved in stimulating the adaptive expression of
Survival Functions

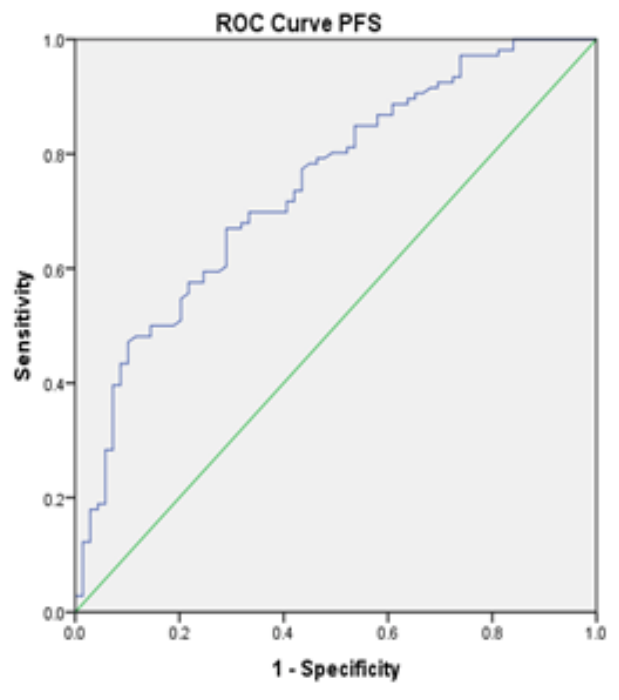

Diagonal segments ace produced by ties.

REV.CHIM.(Bucharest) $70 \diamond$ No. 7 \ 2019

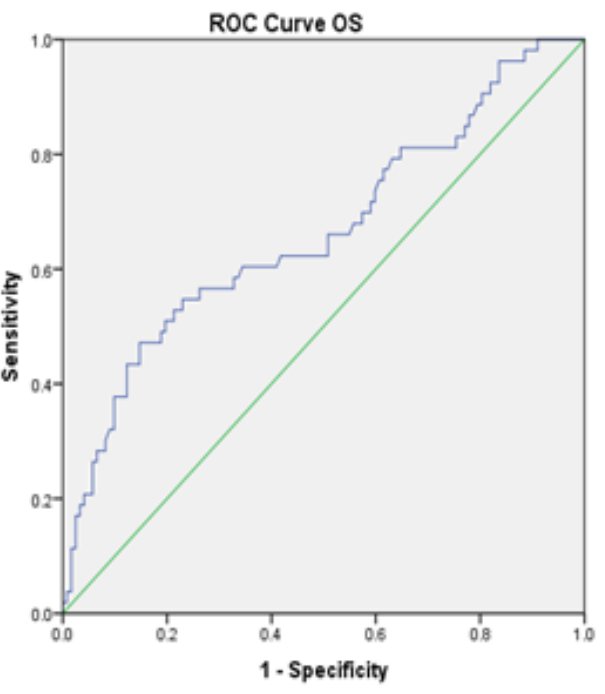

Diagonal sagments are produced by ties.

http://www.revistadechimie.ro
Fig. 3. Roc Curve Representation of the Sensitivity and Specificity of Malondialdehyde (MDA) to Predict Progression Free Survival (A) and Overall Survival (B)
Fig. 2. Progression Free Survival (A) And Overall Survival (B) According to Malondialdehyde (MDA) Groups (Less than $8 \mu \mathrm{mol} / 100 \mathrm{~mL}$, between 8-12 $\mu \mathrm{mol} / 100 \mathrm{~mL}$ And More Than $12 \mu \mathrm{mol} / 100 \mathrm{~mL}$ ). antioxidant enzyme systems such as superoxidedismutase, catalase, and glutathione-S-transferase. A study found that in patients with serum ovarian adenocarcinoma, glathione-peroxidase 3 was extremely low in patients with stage III / IV neoplasia or recurrent disease compared to patients diagnosed with cystadenomas or borderline tumours [21].

The etiopathogenesis of ovarian cancer is not fully understood [22]. As historically, ovarian cancer was divided into four distinct histopathological subtypes (high and low serotype, endometrioid, mucinous), recently a new molecular classification based on miR-200 (small-sized RNA that does not encode information with a role in posttranscriptional gene regulation) seems to have prognostic value [23].

Depending on the gene signature, two important of ovarian cancer have been described: the fibrous subtype, and the oxidative stress subtype. High grade ovarian carcinomas accumulate miR-200 and have a low p38a concentration which is characteristic of the gene signature of the oxidative stress subtype. The oxidative stress subtype has a better prognosis than the fibrous subtype. It is well known that ROS accumulation favours tumour initiation and growth by modulating the proliferation of gene instability and tumour micro medium. However, in ovarian cancer, the impact of ROS is still a controversy. While chronic ROS accumulation stimulates tumour proliferation, ROS may improve the response and sensitivity o chemotherapy in the same time. Patients with tumours classified in the oxidative stress subgroup had statistically significantly longer median survival than those classified in the fibrosis group and that might be explained by the 


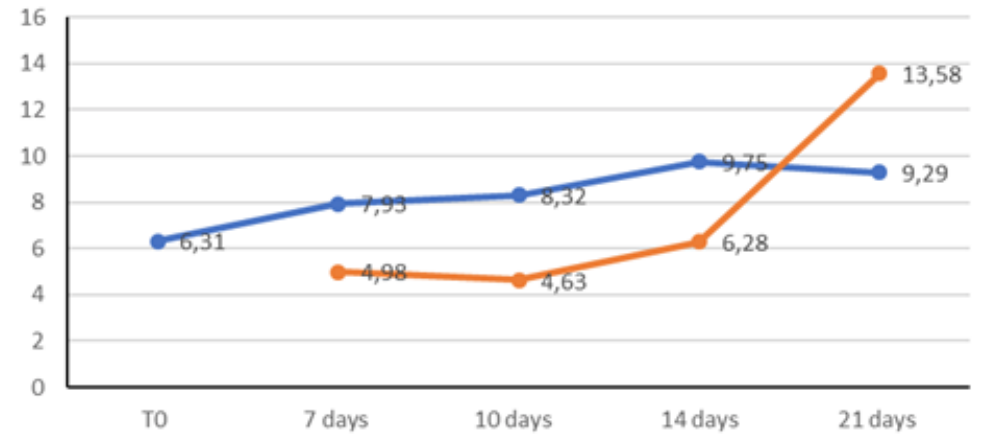

Fig. 4. Increasing Lipid Peroxidation Level (Assessed By Malondialdehyde) in Serum and Tumoural Tissue in Experimental Cancer [22]

fact that patients with tumours with high oxidative stress had a higher complete resection rate and greater sensitivity to chemotherapy, especially to taxanes. While ROS favour tumour growth, on the other hand, the sensitivity to chemotherapy increases, inducing cell death, a phenomenon known as the paradoxical effect of ROS [24].

A study published in 2017 evaluated the role of oxidative stress in patients with ovarian adenocarcinoma ( $n=55$ patients), in patients with benign tumours $(n=20)$, and in healthy patients. The study found out that there was a significant negative association between malignancy and superoxide dismutase and glutathione peroxidase $(p<$ $0.05)$. Moreover, there was a significant positive association between malignancy and MDA $(p<0.05)$. The conclusion of the study was that patients with epithelial ovarian cancer had decreased preoperative serum levels of superoxide dismutase and glutathione peroxidase antioxidants and increased levels of MDA. The study confirmed the role of oxidative stress in the development of epithelial ovarian cancer [25]. Only one study tried to establish the prognostic role of MDA in patients with ovarian carcinoma [26]. A total of 42 patients with newly diagnosed stages I-IV primary ovary cancer were examined. Levels of MDA and catalytic activity catalase were determined spectrophotometrically. Higher MDA levels ( $8.7 \pm 3.0$ vs. $6.7 \pm 2.7 \mathrm{nmol} / \mathrm{L}, p=0.002$ ) were observed in cancer patients compared to healthy volunteers, butno prognostic value was noted in thatstudy, possibly because of the small size of the study group.

Moreover, in another study the mean values of serum MDA and ceruloplasmin were significantly higher in patients with macroscopic residual tumour after surgery compared to patients without residual tumours, the study demonstrating that the tumour was an oxidative stress inducer [27].

In order to confirm the results found in our patients, an experimental model was created.

A lot of 20 Wistar albino female rats were used. Experimental tumour used was Walker 256 carcinosarcoma which is one of the most used tumours in oncologic experiments because of the high rate of successfully transplantation (more than $80 \%$ ), short time to tumour development ( 7 days), and the possibility to develop an ascitic form [28]. The amount of cell injected in the right flank of the abdomen of the rats was $1-2 \times 10^{6} \%$ $\mathrm{mL}$ and blood samples were obtained by cardiac puncture and tumour biopsy at $7,10,14,17$ and 21 days post inoculum. The serum results showed an increasing value of lipid peroxidation measured using MDA as a marker from the first determination $(6.31 \mu \mathrm{mol} / 100 \mathrm{~mL})$ to $9.19, p=$ 0.002 . In tumour tissue the increase was even greater, from 4.28 to $13.58 \mu \mathrm{mol} / 100 \mathrm{~mL}, p=0.001$. These results may be explained by the fact that lipids had a very wide distribution and lipid peroxidation represents the first target of ROS (fig. 4).

Recent studies had showed that MDA and 3-nitrotyrosine measured by liquid chromatography-mass spectrometry were elevated in cultured human hepatoma and might estimate response to treatment and toxicity [29].

\section{Conclusions}

Our study demonstrated that malondialdehyde levels are increased in patients with ovarian adenocarcinoma undergoing adjuvant chemotherapy with paclitaxel and carboplatin after surgery with curative intent and in experimental models.

Moreover, malondialdehyde could be used as a prognostic marker for estimating the progression free survival and overall survival in patients with ovarian adenocarcinoma. Patients with malondialdehyde less than $8 \mathrm{imol} / 100 \mathrm{~mL}$ had a significantly longer PFS and OS than those with a MDA serum level between 8-12 or higher than $12 \mu \mathrm{mol} / 100 \mathrm{~mL}$, validated by ROC curves.

\section{References}

1.COSTANTINI, D., J. Exp. Biol., 222, 2019, 222: jeb194688 doi: 10.1242/ jeb.194688

2.HALLIWELL, B., WHITEMAN, M., Br. J. Pharmacol., 142, no. 2, 2004, p. 231.

3.SHANI, K.H., ZUBAIR, M., RIZWAN, K., RASOOL, N., ERCISLI, S., MAHMOOD, A., ZIA-UL-HAQ, M., DIMA, L., PASCU, A.M., Oxid. Commun., 38, no. 3, 2015, p. 1252.

4.HALICIU, A.M., FOLESCU, R., ZUGUN, F., STRAT, L., POROCH, V., ZAMFIR, C.L., Rev. Chim. (Bucharest), 68, no. 3, 2017, p. 624.

5.EGEA, J., FABREGAT, I., FRAPART YM, Redox. Biol., 13, 2017, pp. 94162.

6.MOLONEY, J.N., COTTER T.G., Semin. Cell Dev. Biol., 80, 2018, p. 50.

7.STANICKA, J., RUSSELL, E.G., WOOLLEY, J.F., COTTER, T.G., J ournal of Biological Chemistry, 290, no. 15, 2015, p. 9348.

8.MOGA, M.A., IRIMIE, M., OANTA, A., PASCU, A., BURTEA, V., Asian Pacific J ournal of Cancer Prevention AJ PC, 15, no. 16, 2014, p. 6887. DOI: 10.7314/APJ CP.2014.15.16.6887.

9.MOLONEY, J.N., STANICKA, J., COTTER, T.G., Leukemia Research, 52, 2017, pp. 34-42.

10.GARCIA-GARCIA, A., RODRIGUEZ-ROCHA, H., MADAYIPUTHIYA, N. Curr. Mol. Med., 12, 2012, pp. 681-697.

11.TSIKAS, D., Analytical Biochemistry, 524, 2017, p. 13e30.

12.NAIR, V., O'NEIL, C.L., WANG, P.G., Encyclopedia of Reagents for Organic Synthesis, John Wiley \& Sons, New York, 2008.

13.BRAY, F., FERLAY, J., SOERJ OMATARAM, I., Cancer J. Clin., 68, 2018, pp. 394-424.

14.LEDERMANN, J.A., RAJA, F.A., FOTOPOULOU, C., GONZALEZMARTIN, A., COLOMBO, N., SESSA, C., Ann. Oncol., 24, Suppl. 6, 2013, pp. vi24-vi32.

15.SAED, G.M., DIAMOND, M.P., FLETCHER, N.M., Gynecol. Oncol., 145, 2017, pp. 595-602. 
16.AGHEORGHIESEI CORODEANU, D.T., POROCH, V., 6th LUMEN International Conference on Rethinking Social Action Core Values, 16-19 April 2015, Iasi, Romania, Rethinking Social Action. Core Values, p. 33.

17.ROGOZEA, L., REPANOVICI, A., CRISTEA, L., BARITZ, M., MICLAUS, R., PASCU, A., Proceedings of the 4th WSEAS/IASME International Conference on Educational Technologies (Edute'08), Book Series: Recent Advances in Computer Engineering, Corfu, Greece, 2008, Oct. 26-28, p. 87.

18.POROCH, V., AGHEORGHIESEI, D.T., Postmodern Openings, 9, no. 2, 2018, p. 225.

19.CARBONNEAU, M.A., PEUCHANT, E,. SESS, D., CANIONI, P., CLERC, M., Clin. Chem., 37, 1991, pp. 1423-1429.

20.COHEN, S., MEHRABI, S., YAO, X., Cancer Res. J., 4, 2016, pp. 06114.

21.AGNANI, D., CAMACHO-VANEGAS, O., CAMACHO, C,. J. Ovarian. Res., 4, 2011, p. 18.
22.CALIN, M.A., MiHALCEANU, E., DEBITA, M., RAFTU, G., COSTACHESCU, G., MITREA, G., Rev. Chim. (Bucharest), 70, no. 3, 2019, p. 1026.

23.MATEESCU, B., BATISTA, L., CARDON, M., Nat. Med., 17, 2011, pp. 1627-1635.

24.BATISTA, L., GRUOSSO, T., MECHTA-GRIGORIOU, F., Int. J. Biochem. Cell Biol., 45, 2013, pp. 1092-1098.

25.RAMADAN, A., HEMIDA, R., NOWARA, A., EISSA, L.A., EL-GAYAR, A.M.J., Exp. Ther. Oncol., 12, no. 1, 2017, pp. 9-15.

26.DIDZIAPETRIENE, J., BUBLEVIC, J., SMAILYTE, G., KAZBARIENE, B., STUKAS, R., Medicina (Kaunas), 50, 2014, pp. 204-208.

27.TRIFANESCU, O., GRUIA,. M.I., GALES, L., TRIFANESCU, R., ANGHEL, R., Chirurgia (Bucuresti), 113, no. 5, 2018, pp. 687-694.

28.SHENOY, P.A., KUO, A., VETTER, I., SMITH, M.T,. Front Pharmacol., 7, 2016, p. 286.

29.VANOVA, N., MUCKOVA L., SCHMIDT, M., HERMAN, D., DLABKOVA, A., PEJ CHAL, J., JUN, D., Biomed. Chromatogr., 32, no. 12, 2018, p. E4349.

$\overline{\text { Manuscript received } 15.12 .2018}$ 